\title{
Peter Broome, In the Flesh of the Text. The Poetry of Marie-Claire Bancquart
}

\section{Rachele Calisti}

\section{(2) OpenEdition}

1 Journals

\section{Edizione digitale}

URL: http://journals.openedition.org/studifrancesi/7720

DOI: 10.4000/studifrancesi. 7720

ISSN: 2421-5856

\section{Editore}

Rosenberg \& Sellier

\section{Edizione cartacea}

Data di pubblicazione: 1 décembre 2009

Paginazione: 669

ISSN: 0039-2944

\section{Notizia bibliografica digitale}

Rachele Calisti, «Peter Broome, In the Flesh of the Text. The Poetry of Marie-Claire Bancquart», Studi

Francesi [Online], 159 (LIII | III) | 2009, online dal 30 novembre 2015, consultato il 09 janvier 2021. URL: http://journals.openedition.org/studifrancesi/7720 ; DOI: https://doi.org/10.4000/studifrancesi.7720

Questo documento è stato generato automaticamente il 9 janvier 2021.

\section{(c) (i) $\odot$}

Studi Francesi è distribuita con Licenza Creative Commons Attribuzione - Non commerciale - Non opere derivate 4.0 Internazionale. 


\title{
Peter Broome, In the Flesh of the Text. The Poetry of Marie-Claire Bancquart
}

\author{
Rachele Calisti
}

\section{NOTIZIA}

PETER BROOME, In the Flesh of the Text. The Poetry of Marie-Claire Bancquart, Amsterdam-New York, Rodopi, 2008 («Collection monographique Rodopi en littérature française contemporaine», 47), pp. 270.

1 «L'autoportrait que je préférerais, ce serait un portrait à la manière d'Arcimboldo», ovvero il pittore di soggetti mille volte mutevoli e indeterminabili, metamorfosi insolite che nascondono sempre un senso più intimo e enigmatico, impercettibili germinazioni dell'io che suscitano stupore e meraviglia. Così si descrive Marie-Claire Bancquart e così l'avvicina Peter Broome, mettendo il lettore a contatto con tutte le sfumature, le variazioni, le dissimmetrie di una poesia che è considerata in primo luogo «as a live instrument» (p. 11). L'analisi di Broome, perciò, proprio per meglio seguire una poesia interamente condizionata dai moti dell'animo, si fa a sua volta dinamica, malleabile, si trasforma in un'avventura che sa stupirsi ogni volta delle improvvise scoperte che il testo rivela. Per questo di tale poesia l'A. non indaga solo il senso più evidente, lo stile o la sintassi, ma vuole di più: chiede di penetrarne la pelle e la carne, per aderire anch'egli intimamente al progetto empatico della stessa Bancquart. Una critica testuale così prossima all'autrice, così approfondita da entrare in simbiosi con la poetessa e i suoi versi, seguendone le evoluzioni, gli impulsi, gli improvvisi arresti e le ripartenze, mostra una vicinanza che si trasmette al lettore, che non solo comprende la poesia, ma visceralmente se ne appropria per approfondirla con i suoi mezzi e le risorse personali. Si instaura così un nuovo legame con il testo, quasi un rapporto d'amore che sensualmente sfiora l'epidermide delle parole per poi penetrarle più a fondo, oltre il senso superficiale, fin dove Marie-Claire Bancquart spinge gli echi della sua poesia. Il lettore riscopre ancora e ancora la carne dei diversi significati messi a nudo, creando una nuova connessione di frasi, un ennesimo circuito di forze, in cui il senso viene 
svelato proprio grazie alla pienezza della sua lettura e si riflette di nuovo in un altro io sempre imprevedibile e sfuggente, mai assimilabile né tantomeno comprensibile, semplicemente desiderabile, in un continuo e precario rilancio tra bisogno e compimento, ricerca e soddisfazione.

2 Broome, nell'addentrarsi nella vasta produzione di Marie-Claire Bancquart, opera due scelte ben precise: prende in considerazione solo sette delle sue opere (da qui le sette parti in cui la monografia è divisa) e all'interno di queste analizza più specificatamente solo alcune poesie, inserendole sempre però nel senso globale dell'intera raccolta e nel passato della più alta tradizione francese, in uno scambio costante tra la vitalità propria di ogni singola poesia e la sua intensità riflessa in un movimento totalizzante che percorre l'opera tutta, tramite l'intrecciarsi e il riflettersi di sensi acquisiti mediante l'influenza dei versi che precedono e seguono ogni singolo componimento. Così la poesia della Bancquart "crea spazi" sulla pagina concreta e spazi virtuali, suggeriti dal vibrare delle sensazioni, dalle variazioni dell'io, dalle corrispondenze tra parole, dai rimandi nel tempo e nella memoria e persino nella violenza generata da un dinamismo troppo esuberante: aspettative e desideri, appuntamenti a cui non bisogna mancare, proprio là dove «the word, marvellously, becomes flesh» (p. 20) e permette di gustare la poesia come fosse amore. 